\title{
Recombinant hemangiopoietin promotes cell adhesion and binds heparin in its multimeric form
}

\author{
LI-FANG WANG ${ }^{1}$, ZHI-BO HAN ${ }^{2}$, MEI LI $^{3}$, PING YANG ${ }^{2}$, BIN XV ${ }^{4}$, \\ JI-PING ZHANG ${ }^{3}$ and ZHONG-CHAO HAN ${ }^{2,4}$
${ }^{1}$ Department of Basic Medicine, Zhejiang Medical College, Hangzhou 310053; ${ }^{2}$ State Key Laboratory of Experimental Hematology, Institute of Hematology and Hospital of Blood Diseases, Chinese Academy of Medical Sciences and Peking Union of Medical College, Tianjin 300020; ${ }^{3}$ National Laboratory of Biomacromolecules, Institute of Biophysics, Chinese Academy of Sciences, Beijing 100010; ${ }^{4}$ National Research Center for Stem Cell Engineering and Technology, Tianjin 300020, P.R. China

Received September 20, 2012; Accepted January 4, 2013

DOI: $10.3892 / \mathrm{mmr} .2013 .1274$

\begin{abstract}
Hemangiopoietin (HAPO) is a novel growth factor stimulating the proliferation of hematopoietic and endothelial progenitor cells in vitro and in vivo. The native protein is a 294-amino acid multimodular protein. The N-terminus constitutes of two somatomedin B (SMB) homology domains that contain 14 cysteines. The central region is a putative heparin-binding domain (pHBD) and the C-terminus contains mucin-like repeats. In the present study, we demonstrated that prokaryotic recombinant human HAPO (rhHAPO) self-associates into a multimeric form with a mass weight of $\sim 129 \mathrm{kDa}$, suggesting a homologous tetramer. rhHAPO in its multimeric form was found to be more stable and more potent in promoting HESS-5 cell adhesion. Multimeric rhHAPO had a higher affinity to heparin compared with its dimeric form, although there was no significant conformational change. C-terminal repeats-truncated rhHAPO (rhHAPO $\Delta$ mucin) was also found to be assembled into a multimer, while deletion of pHBD (rhHAPO $\triangle$ mucin-pHBD) caused the protein to remain in a dimeric form, demonstrating that SMB domains participate in self-aggregation of the molecule and that the pHBD region promotes the tetramerization.
\end{abstract}

\section{Introduction}

Hemangiopoietin (HAPO), a 294-amino acid protein, stimulates the proliferation and hematopoiesis and/or endothelial

Correspondence to: Professor Zhong-Chao Han, State Key Laboratory of Experimental Hematology, Institute of Hematology and Hospital of Blood Diseases, Chinese Academy of Medical Sciences and Peking Union of Medical College, 41 Damucang Road, Xicheng, Tianjin 300020, P.R. China

E-mail: zhongchaohan56@126.com

Key words: hemangiopoietin, aggregation, heparin, cell adhesion, prokaryotic expression differentiation of human bone marrow mononuclear cells and of purified CD34+, CD133+, kinase domain receptor-positive (KDR+) or CD34+/KDR+ cell populations (1). The native protein is one of the alternative splicing products of proteoglycan 4 (PRG4), which consists of 12 exons. The coding sequence of native HAPO includes part of exon 2, full-length exons 3 and 4 and part of PRG4 exon 6. Research performed to date supports the assignment of at least three domains within HAPO: i) The N-terminal domain encoded by PRG4 exons 2 and 3 consists of two somatomedin B (SMB) homology domains $\left(\mathrm{SMB}_{\text {rhHAPO}}\right)$, while HAPO lacks N-terminal 15 amino acids in exon 2. SMB, with the consensus sequence $\mathrm{X}_{2} \mathrm{CX}_{6} \mathrm{CX}_{9} \mathrm{CXCX}_{3} \mathrm{CX}_{5} \mathrm{CCX}_{5} \mathrm{CX}_{5}$, is homologous to the cysteine-rich region of vitronectin ( $\mathrm{Vn}$ ) and the sequence identity is $45 \%$ (2). All 14 cysteines of HAPO are distributed over the two SMB domains. ii) The center region of HAPO encoded by PRG4 exon 4 is a lysine $(\mathrm{K})$-rich region with the probable function of heparin binding and is known as putative heparinbinding domain (pHBD) (2). The interaction between protein and heparin is one of the most investigated topics in previous studies, particularly the mechanism of promoting cell adhesion. iii) The C-terminus encoded by PRG4 exon 6 is a mucin-like $\mathrm{O}$-linked oligosaccharide-rich repeat region composed of KEPATTT/P and XXTTTX consensus sequences (2). These repeats are highly diverse in length among species (3).

PRG4, an extracellular matrix (ECM) protein, has been identified as megakaryocyte-stimulating factor (MSF) or cartilage superficial zone proteoglycan (SZP) encoded by the DOL54 gene. Two tissue-specific alternative splice variants of PRG4 have been detected in human pathological tendon by polymerase chain reaction (PCR) with forward primers specific for exon 3 in combination with a reverse primer specific for exon 6. One splice variant, similar to HAPO, lacks exon 5, while the other lacks exons 4 and 5 (3-6).

The recombinant HAPO expressed in E. coli supported the survival of MO7e cells through a PI3K-Akt pathway following deprivation of granulocyte-macrophage colony stimulating factor (7). The transfection of the HESS-5 mouse bone marrow stromal cell line with a eukaryotic HAPO-expressing vector 
supported the rapid generation of primitive progenitor cells and maintains reconstitution of $\mathrm{CD} 34^{+}$hematopoietic stem cells in vitro (8).

HAPO has clinical potential in the management of various cytopenias and radiation injury. However, there is limited knowledge with regard to its biophysical characteristics. In this study, we cloned and expressed the full-length protein and two deletion mutants. Biophysical experiments were also performed in order to gain knowledge of the protein structure.

\section{Materials and methods}

Expression and purification of rhHAPO and the mutation variants. The complementary DNA (cDNA)-encoding full length HAPO was amplified by PCR from human fetal liver cDNA and inserted into plasmid pET22b (+) (Novagen, Madison, WI, USA) which had been digested with $\mathrm{NcoI}$ and $X h o I$ as previously described. The human fetal liver was obtained from aborted fetuses of 17-22 weeks' gestation after informed consent was obtained (1).

The protein was extracted using the one-step extraction method. The cells were suspended into three volumes of $20 \%$ sucrose, $1 \mathrm{mM}$ ethylenediaminetetraacetic acid (EDTA) and $20 \mathrm{mM}$ Tris- $\mathrm{HCl}$ ( $\mathrm{pH}$ 7.9). Seven times volume ice water was then added. Following centrifugation at $12,000 \mathrm{rpm}$ for $30 \mathrm{~min}$ at $4^{\circ} \mathrm{C}$, the supernatant was loaded to a nickel-chelating column. The fraction washed from the affinity column containing His-bind resin with $0.5 \mathrm{M} \mathrm{NaCl}, 200 \mathrm{mM}$ imidazol and $20 \mathrm{mM}$ Tris- $\mathrm{HCl}$ (pH 7.9), was dialyzed into $20 \mathrm{mM}$ citrate sodium buffer ( $\mathrm{pH}$ 5.5) and then applied to a fast flow SP Sepharose ${ }^{\mathrm{TM}}$ column. The target protein was eluted at the same buffer with $0.5 \mathrm{M} \mathrm{NaCl}$.

The cDNA of rhHAPO $\Delta$ mucin and rhHAPO $\Delta$ mucinpHBD was amplified from human fetal liver cDNA using the 5 (5'-CATgCCATggATgCCACCTgCAACTgTgA-3') and $3^{\prime}$ (5'-CTAgCTCgAgAgTTgTgACCTTgAAgTCAC-3') oligonucleotide primers. The amplified cDNA products were digested with $N c o$ I and $X h o$ I. The rhHAPO $\Delta$ mucin cDNA was inserted into pET22b (+) and the rhHAPO $\triangle$ mucin-pHBD cDNA was inserted into pET32c (+). The purification of rhHAPO $\triangle$ mucin mutant was performed as described above for the full-length HAPO. For the purification of the rhHAPO $\triangle$ mucin-pHBD, the protein was eluted by $160 \mathrm{mM}$ imidazol, $0.5 \mathrm{M} \mathrm{NaCl}$ and $50 \mathrm{mM}$ Tris- $\mathrm{HCl}$ (pH 8.0), dialyzed into $20 \mathrm{mM}$ Tris- $\mathrm{HCl}$ ( $\mathrm{pH}$ 8.0) and excised with enterokinase ( $3 \mathrm{U} / \mathrm{mg}$ protein; Invitrogen, Carlsbad, CA, USA) at $4^{\circ} \mathrm{C}$ for $16 \mathrm{~h}$. The peptide and the enzyme were separated with Resource Q (GE Healthcare Bioscience Corp., Piscataway, NJ, USA) at 0-0.5 M NaCl. The protein concentration was determined by measuring absorbance (A) at $280 \mathrm{~nm}$ with a U-3010 spectrophotometer (Hitachi High-Technologies Corporation, Tokyo, Japan) and using a calculated extinction coefficient given by ExPASy-ProtParam tool (http://kr.expasy.org/tools/protparam.html).

Size-exclusion chromatogaraphy. Following dialyzation into $20 \mathrm{mM}$ Tris- $\mathrm{HCl}$ (pH 8.0), rhHAPO eluted from Reasource Q was applied to a Superdex 200 10/300 GL column (Amersham Pharmasia Biotech, Piscataway, NJ, USA) at $0.5 \mathrm{ml} / \mathrm{min}$. Purified rhHAPO $\triangle$ mucin and rhHAPO $\triangle$ mucin-pHBD were dialyzed into phosphate-buffered saline (PBS) and applied to a Superdex 200 10/300 GL column. The column had a void volume (Vo) of $8.3 \mathrm{ml}$ and the standards IgG1 $(150 \mathrm{kDa})$, bovine serum albumin (BSA; $67 \mathrm{kDa})$ and lysozyme $(14.4 \mathrm{kDa})$ eluted at $12.305,14.345$ and $17.147 \mathrm{ml}$ (Ve), respectively. The elution volumes of the standards were divided by the elution volume of the thyroglobulin $(\mathrm{Ve} / \mathrm{Vo})$ and plotted against the log of the molecular weights of the standards. Then, the molecular masses of the peaks of rhHAPO could be measured.

Western blot analysis. Western blot analysis was routinely performed. Following electrophoresis and transfer, the blotted membrane was blocked in Tris-buffered saline (TBS) buffer (PBS, $0.02 \%$ Tween-20) containing 5\% non-fat dried milk for $1 \mathrm{~h}$ at room temperature. The membrane was then incubated with anti-rhHAPO MoAb prepared by the laboratory of National Research Center for Stem Cell Engineering and Technology in TBS buffer overnight at $4^{\circ} \mathrm{C}$ and horseradish peroxidase-conjugated goat anti-mouse IgG (Beijing Zhongshan Biotechnology Co., Beijing, China) for $1 \mathrm{~h}$ at room temperature.

Dynamic light-scattering (DLS) analysis. HAPO and rhHAPO $\triangle$ mucin-pHBD were dialyzed into PBS $(1 \mathrm{mg} / \mathrm{ml})$. DLS was carried out to characterize the aggregating with Protein Solutions DynaPro (Protein Solutions, Charlottesville, VA, USA). DLS was recorded on a DynaPro-801 (Protein Solutions) with a temperature-controlled microsampler at $20^{\circ} \mathrm{C}$. Twenty scans were averaged for each measurement. Dynamics version 5.24.02 instrument software was used to analyze the data.

Mass spectrum assay. The second fraction $(1 \mathrm{mg} / \mathrm{ml})$ of rhHAPO eluted from Superdex 200 was dialyzed into water and matrix-assisted laser desorption-ionization time-of-flight mass spectrometry (MALDI-TOF-MS) was performed for molecular weight analysis (National Center of Biomedical Analysis, Beijing, China).

Isoelectrofocusing. The pI values of rhHAPO and rhHAPO $\triangle$ mucin-pHBD were calculated using the ExPASyProtParam tool. Isoelectrofocusing was performed to examine the purification and check their $\mathrm{pI}$ with the method suggested by the manufacturer (Instruction 1818-A, LKB-Produkter AB, Bromma, Sweden) using a 0.55 -mm thin-layer polyacrylamide gel, ampholine carrier ampholytes $(\mathrm{pH}$ 3.5-9.5; LKB-Produkter $\mathrm{AB})$. rhHAPO and pHBD were dialyzed into water and $20 \mu \mathrm{l}$ $1 \mathrm{mg} / \mathrm{ml}$ protein was loaded into the loading filter paper. The marker was broad pI calibration kit (pI 3.5-9.3; Amersham Pharmasia Biotech). Following electrofocusing, the gel was stained with Coomassie blue and the pI was monitored.

Cell adhesion assay. The murine bone marrow stromal cell line HESS-5 was routinely cultured in Iscove's modified Dulbecco's medium (IMDM) containing 10\% fetal calf serum, $1 \%$ Gln, $1 \%$ penicillin-streptomycin. Ninety-six-well plates were coated with $0.5 \% \mathrm{BSA}$ at $4^{\circ} \mathrm{C}$ overnight and washed with PBS twice to prevent non-specific adhesion. HESS- 5 cells $\left(5 \times 10^{4}\right)$ were plated into every well with IMDM medium containing $2 \%$ fetal calf serum, $1 \%$ Gln and $1 \%$ penicillin-streptomycin. rhHAPO in dimeric or mulimeric forms $(1,000 \mathrm{ng} / \mathrm{ml})$ was added. The recombinant proteins were separated from rhHAPO by size-exclusion chromatogaraphy with 
A

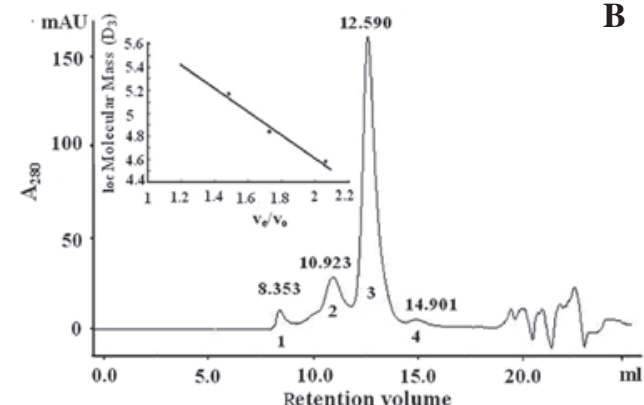

C

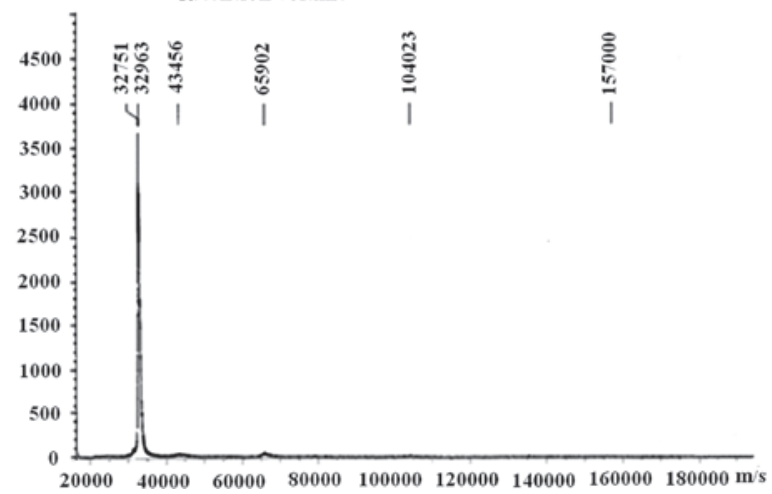

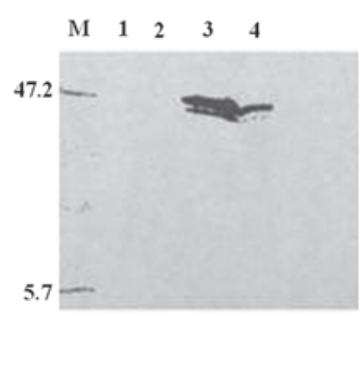

ถั.

Figure 1. Identification of multimeric recombinant human hemangiopoietin (rhHAPO). (A) Superdex 200 10/300 GL column chromatography of rhHAPO with phosphate-buffered saline (PBS) buffer at $0.5 \mathrm{ml} / \mathrm{min}$ elution speed. rhHAPO was isolated into several peaks (1-4). (B) Western blot analysis for the four peaks. (C) Matrix-assisted laser desorption-ionization time-of-flight mass spectrometry (MALDI-TOF-MS) of tetrameric rhHAPO.

Superdex 200. Cells were cultured at $37^{\circ} \mathrm{C}$ for $2 \mathrm{~h}$, the supernatant was then removed and the cells were washed twice with PBS. The crystal violet method was performed to measure $A$ at $596 \mathrm{~nm}$. Ratio of relative adhesion $=\left[\left(\mathrm{A}_{\mathrm{HAPO}^{-}}\right) /\left(\mathrm{A}_{\mathrm{PBS}}\right)\right] \times 100$.

Heparin binding assay. Heparin binding assay was performed as previously described (9). Protein was applied to a $1 \times 5-\mathrm{cm}$ heparin agarose column in $20 \mathrm{mM}$ Tris- $\mathrm{HCl}$ buffer $(\mathrm{pH} 7.4)$ and eluted at a flow rate of $1 \mathrm{ml} / \mathrm{min}$ with a $\mathrm{NaCl}$ gradient in the same buffer. A was monitored at $280 \mathrm{~nm}$. $\mathrm{NaCl}$ concentration was determined by conductivity.

Circular dichroism (CD). The CD spectrum was performed on a Jasco J720 spectropolarimeter (Jasco, Easton, MD, USA). Far UV measurements were taken in a $0.1-\mathrm{cm}$ path length utensil with rhHAPO dialyzed into PBS buffer. Time constants were $4 \mathrm{sec}$ and 5 scans were averaged for each measurement. CD was expressed in terms of ellipticity $[\theta]$ in degree $\mathrm{x} \mathrm{cm}^{2} / \mathrm{dmol}$. Low molecular weight (LMr) heparin was purchased from SigmaAldrich (St. Louis, MO, USA). To determine whether rhHAPO binds to heparin, solutions containing protein plus heparin were prepared at various protein:heparin ratios (w/w). CD was performed to analyze the conformational change. The K2D program (http://kal-el.ugr.es/k2d/spectra.html) was used for the prediction of protein secondary structure from CD spectra.

\section{Results and Discussion}

rhHAPO is a stable tetramer. In the gel filtration chromatogram by Superdex 200 300/10 GL column chromatography, there were four A peaks of rhHAPO purified from SPFF with the first peak eluted at void volume suggesting matter with a high molecular weight (Fig. 1A). Western blot analysis with
anti-rhHAPO MoAb was performed to identify the peaks (Fig. 1B). The first two peaks did not contain the protein recognized by the rhHAPO antibody and after the endotoxin was removed from the sample, fraction 1 disappeared (data not shown), suggesting that this peak was mostly composed of endotoxin. According to the retention volume of standards, the calculated molecular mass of fractions 3 (principal component) and 4 was 129.8 and $65.2 \mathrm{kDa}$ (Fig. 1A), respectively. Since the theoretical molecular weight deduced from amino acid sequence of rhHAPO with (His) ${ }_{6}$-tag was 32,742.6 Da, rhHAPO is likely to be a homotetramer with a trace amount of the dimeric form. Fraction 3 was expected to be a 137-kDa protein calculated by DLS. This was consistent with the results from gel filtration, suggesting a tetrameric form of rhHAPO.

MALDI-TOF MS was then used to obtain a more accurate measurement of the mass weight of the protein in peak 3 . The result gave a perfect peak with a molecular weight of $32,751 \mathrm{Da}$ (Fig. 1C), the mass weight of one rhHAPO molecule. The electronic energy of MALDI-TOF MS changed the multimeric conformation of rhHAPO into a monomer.

Multimeric rhHAPO is more potent in promoting cell adhesion than the other form. HESS-5 cell adhesion assay was performed to determine the different efficacy between the monomer, dimer and tetramer structures of rhHAPO. HESS-5 is a murine bone marrow stroma cell line that supports the reconstituting ability of ex vivo-generated hematopoietic stem cells from human bone marrow and cytokine-mobilized peripheral blood (10). When HESS-5 cells were cultured in the presence of the tetrameric HAPO, increased adhesion was observed compared with the presence of the dimeric HAPO (relative adhesion value $=54.3 \pm 11.1$ vs. $33.2 \pm 12.1 \% ; \mathrm{P}=0.033$ ). Platelet $\mathrm{Vn}$ is another protein known to promote endothelial 

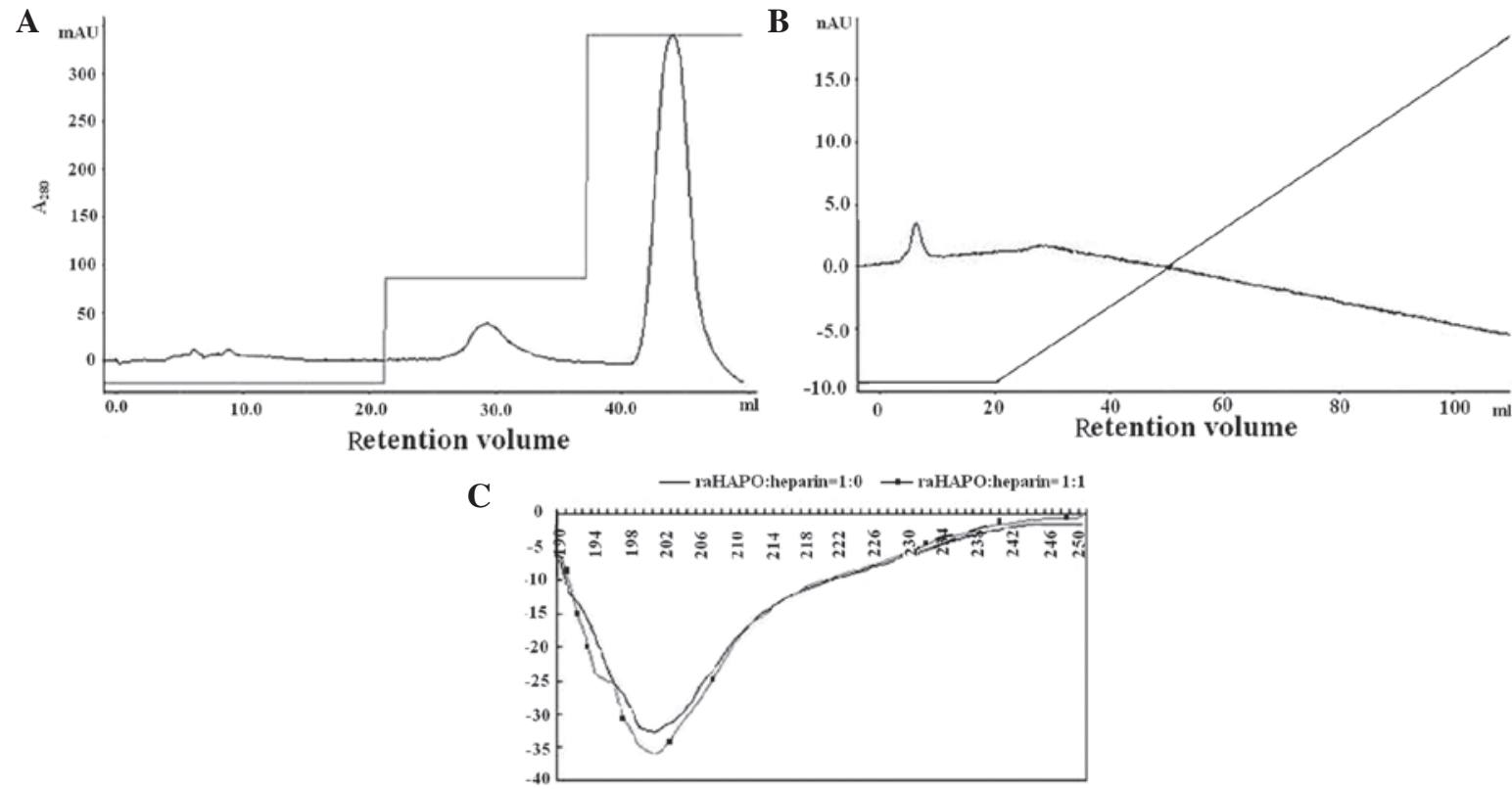

Figure 2. Heparin binding assay. (A) Tetrameric recombinant human hemangiopoietin (rhHAPO) was applied to a heparin column. The protein was quantitatively retained on the column and eluted at $1 \mathrm{M} \mathrm{NaCl}$, while there was no significant peak in loading procedure. (B) Monomeric rhHAPO was applied to a heparin column. No significant peak was observed within a 0-2 $\mathrm{M} \mathrm{NaCl}$ elution, while there was a peak when the peptide was loaded to the agarose. The concentration of $\mathrm{NaCl}$ is shown linearly. (C) Far-ultraviolet (UV) circular dichroism spectra measurements of tetrmeric rhHAPO with phosphate-buffered saline (PBS) buffer in the absence of heparin (1:0) indicated a random coil conformation (peaks at $200 \mathrm{~nm}$ ). However, it retained the conformation in the presence of different concentrations of heparin (1:1). Data were collected at $20^{\circ} \mathrm{C}$.

cell adhesion and the conformationally altered multimeric $\mathrm{Vn}$ is more potent compared with the monomeric form (11). Binding efficiency of multimeric Vn with porcine endothelial cells monolayer is 3-4 times higher compared with monomeric Vn (11). A possible explanation for this different behavior is the steric influence due to aggregation. A number of studies suggest that the SMB domain is indeed cryptic in native monomeric Vn (12). Highly sulfated glycosaminoglycans (GAGs) bind to native plasma $\mathrm{Vn}$ and induce Vn multimerization at physiological ionic strength, resulting in the exposure of the SMB domain. Although the principal site for cell attachment in Vn is the Arginine-Glycine-Aspartic (RGD) sequence locating in the SMB domain, it has been confirmed that the purified recombinant SMB domain, which does not contain the RGD sequence, is able to promote the attachment of HT-1080 and U937 cells (13). Multimeric Vn is able to bind the endothelial cells through the heparin-binding domain, not the RGD sequence (14). Due to the high sequence homology between Vn and HAPO, it is possible that dimeric HAPO self-associates into the tetrmeric form, which may cause a structural change and consequently SMB or heparin-binding domain exposure, thus facilitating binding to their receptors.

Multimeric rhHAPO is more potent in binding heparin compared with the monomeric rhHAPO in the absence of significant conformational change. Heparin-binding peptides from ECM proteins have been identified to promote cell adhesion $(8,15)$. Direct binding of the peptide to heparin may be assessed by affinity chromatography on a heparin-agarose column. High binding activity was evaluated from rhHAPO tetramer interactions with heparin-agarose column at $1 \mathrm{M} \mathrm{NaCl}$ elution (Fig. 2A). However, during the elution procedure with a linear salt gradient of 0-1.0 M NaCl, dimeric rhHAPO was eluted with loading buffer and did not bind heparin (Fig. 2B). There was a molecular weight dependence of rhHAPO binding to heparin. This notable observation was similar to $\mathrm{Vn}$ (16). Vn association into a multivalent form contains proximal aligned heparin-binding sites exposed on its surface and has been shown to have a stronger binding activity due to the increased number of heparin-binding sites (17). A similar phenomenon may explain why the tetrameric rhHAPO was more effective in promoting cell adhesion compared with the monomeric rhHAPO.

The far-ultraviolet CD spectrum of multimeric rhHAPO is shown in Fig. 3. There was no significant structural change after binding with heparin (Fig. 2C). This spectrum differs significantly from $\mathrm{CD}$ spectra of proteins known to assume disordered structure. The spectrum gives a strong negative ellipticity maximum at $200 \mathrm{~nm}$, while weak positive ellipticities are not observed at $218 \mathrm{~nm}$. Although a negative signal near $200 \mathrm{~nm}$ may be associated with disordered structure, the broad nature of the band suggested some structural contribution. This spectrum was characteristic of rhHAPO with predominant $\beta$-sheets and random coils, with limited $\alpha$-helical content (18). Analysis of this CD spectrum using K2D online software indicated that rhHAPO is $61 \%$ random coils, $27 \%$ $\alpha$-helices and the remainder is $\beta$-sheets.

$S M B$ and $p H B D$ is the oligomerization region of mulitimetic rhHAPO. Denaturation and renaturation of Vn under physiological solution conditions is invariably accompanied by self-association of the protein into a multimeric form (19). Intermolecular disulfide cross-linking occurs primarily at the multimeric Vn. We predicted a three-dimensional structure model of the first $\mathrm{SMB}_{\text {rhHAPO }}$ with swissmodel (http://swissmodel.expasy.org/) (20) to investigate the disulfide model. The proposed disulfide linkage was $\mathrm{Cys}^{5}-\mathrm{Cys}^{9}, \mathrm{Cys}^{19}-\mathrm{Cys}^{31}$, 
Table I. Comparison of characteristics of rhHAPO and rhHAPO $\Delta$ mucin-pHBD.

\begin{tabular}{lcccc}
\hline Protein & Monomer $(\mathrm{kDa})$ & Oligomer (kDa) & pI & $\begin{array}{c}\text { Predicted extinction } \\
\text { coefficients }^{\mathrm{a}}\left(\mathrm{M}^{-1} \mathrm{~cm}^{-1}\right)\end{array}$ \\
\hline rhHAPO & 32.7 & 129.8 & 8.52 & 5,960 \\
rhHAPO $\Delta$ mucin-pHBD & 12.9 & 28.6 & 6.39 & 6,835 \\
\hline
\end{tabular}

${ }^{a}$ Values were computed at $280 \mathrm{~nm}$ assuming the Cys residues appear as half cysteines. rhHAPO, recombinant human hemangiopoietin.
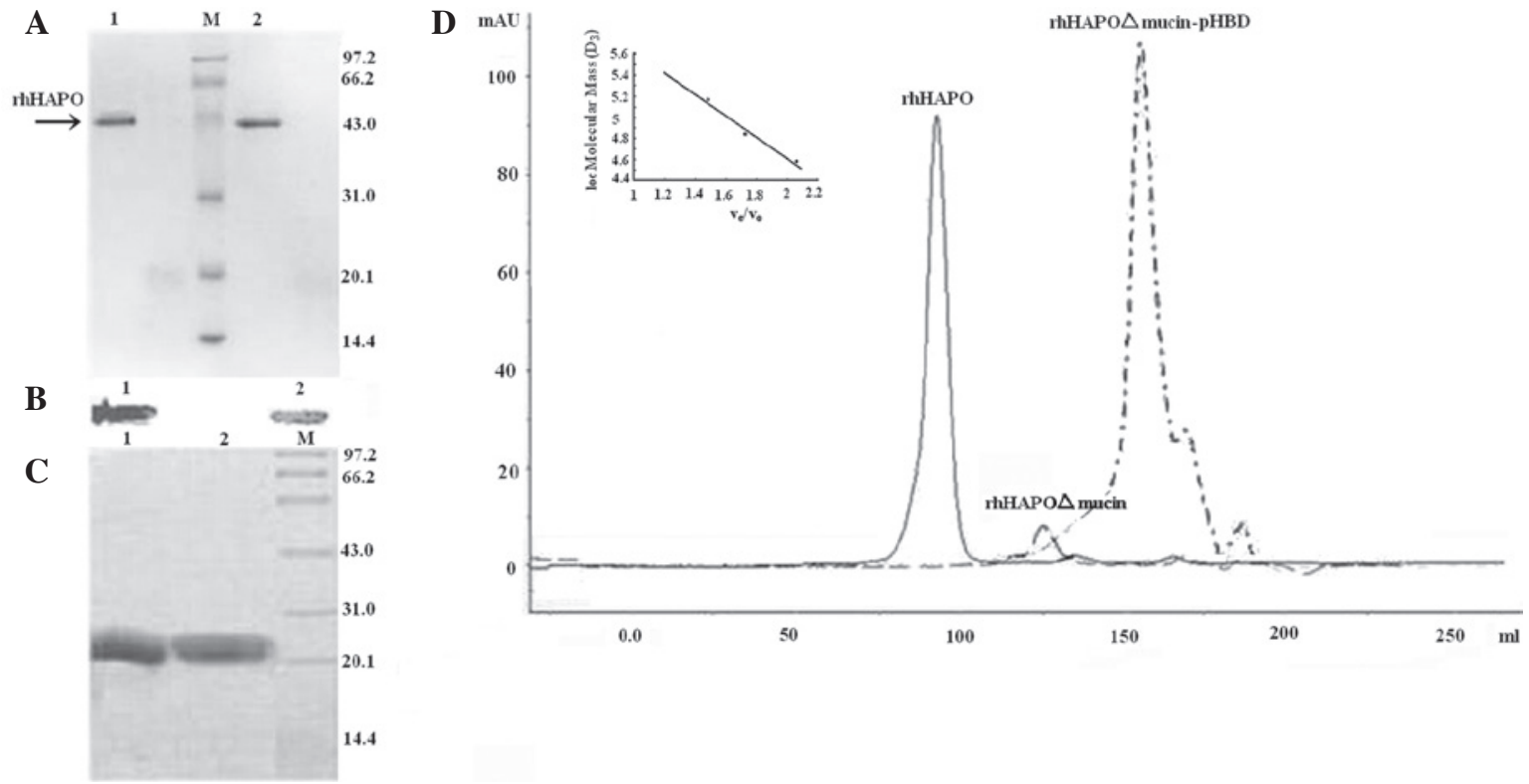

Figure 3. Identification of the oligomerization region of multimeric recombinant human hemangiopoietin (rhHAPO). (A) rhHAPO was analyzed by SDS-PAGE on 15\% reducing (lane 1) and non-reducing (lane 2) polyacryamide gels stained with Coomassie blue. Molecular weight markers (M) were in $\mathrm{kDa}$. (B) Western blot analysis for reducing (lane 1) and non-reducing (lane 2) electrophoresis. (C) Reducing (lane 1) and non-reducing (lane 2) SDS-PAGE of rhHAPO $\Delta$ mucin-pHBD. (D) Superdex $200300 / 10 \mathrm{GL}$ column chromatography of rhHAPO $\Delta$ mucin-pHBD and rhHAPO $\Delta$ mucin with phosphate-buffered saline (PBS) buffer at $0.5 \mathrm{ml} / \mathrm{min}$ elution speed.

$\mathrm{Cys}^{21}-\mathrm{Cys}^{32}$ and $\mathrm{Cys}^{25}-\mathrm{Cys}^{39}$. In this pattern, the first two cysteines form an independent disulfide bond. The first SMB domain of the native HAPO purified from patients and rhHAPO lack the N-terminal 15 amino acids containing these two cysteines. Thus, absence of these 15 amino acids does not appear to form dissociated cysteines in the molecule.

The results of reducing and non-reducing SDS-PAGE further supported our hypothesis. On SDS-PAGE under reducing and non-reducing conditions, the multimeric protein migrated as a single band with a molecular mass of $\sim 42 \mathrm{kDa}$ (Fig. 3A and B). The results showed that disulfide bond was not involved in the aggregation. There was no free sulfhedryl in rhHAPO as well as the result of recombinant $\mathrm{SMB}_{\mathrm{Vn}}$ mensurated by Ellman's method (21). Under non-reducing conditions, the mobility of rhHAPO was slightly increased. This was caused by 14 cysteines being distributed over the SMB domain (22). The protein amount of positive charges or cysteines does not have a lineal correlation with the relative migratory ratio and molecular weight. Meanwhile, there was a high content of positively charged amino acids throughout the full length HAPO. Sequence analysis showed that is a K-rich protein with $14.3 \%$ Lysine amino acid residues. The ratio of positively charged residues $(K+R)$ to negatively charged residues $(D+E)$ was $50 / 38$.

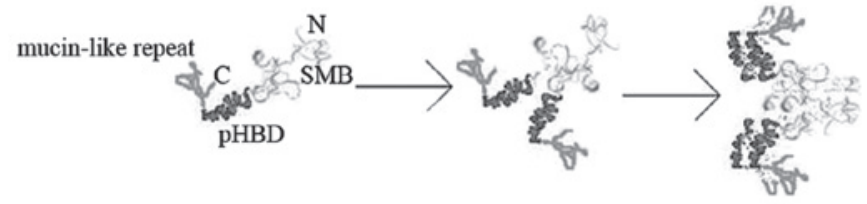

Figure 4. Potential model to account for the oligomerization of recombinant human hemangiopoietin (rhHAPO). The monomeric rhHAPOs were assembled into a dimer by interactions between somatomedin B (SMB) domains. This interaction caused a conformational change in the putative heparin-binding region ( $\mathrm{pHBD}$ ) which then mediated the association of the dimer into a tetramer.

To identify the oligomerization sequence, we investigated the consequences of the absence of the mucin-like domain. According to the amino acid sequence, the predicted molecular weight of rhHAPO $\Delta$ mucin was $18.2 \mathrm{kDa}$, whereas the calculated molecular weight was $72.4 \mathrm{kDa}$ in Superdex 200 size-exclusion chromatogaraphy (Fig. 3D), suggesting that the protein was also a stable tetramer. We found that deletion of the mucin-like repeat did not hamper the ability of rhHAPO to form a tetramer. C-terminal mucin-like repeats did not participate in the oligomerization. 
Based on the alternative splicing of PRG4 mRNA, a cDNA lacking the center region $\mathrm{pHBD}$ was amplified with the same primers as those of rhHAPO $\Delta$ mucin. In Superdex 200 300/10 GL column chromatography, the retention volume of rhHAPO $\triangle$ mucin-pHBD was $17.98 \mathrm{ml}$ (Fig. 3D) with the calculated molecular mass $28.2 \mathrm{kDa}$, validating the dimeric form of rhHAPO $\Delta$ mucin-pHBD. The recombinant $\mathrm{SMB}_{\mathrm{V}_{\mathrm{n}}}$ with $\mathrm{C}$-terminal of thioredoxin had monomeirc and dimeric form (23). The two N-terminal SMB domains of nucleotide pyrophosphatases/phosphodiesterases 1 (NPP1) were disulphide-linked homodimers and dimers could even be detected after reducing SDS-PAGE (24). However, we found that recombinant $\mathrm{SMB}_{\mathrm{HAPO}}$ was a non-covalent dimer by reducing and non-reducing SDS-PAGE (Fig. 3C). Expression of this deletion mutant protein resulted in structural alternations. Thus, SMB and pHBD consisted of an intact tetramer. The absence of pHBD caused the protein to be a dimer and changed certain physical characteristics of the protein (Table I). It has been proposed that the heparin-binding domain in Vn mediates the protein association, but this conclusion has been disproved in biochemical and biophysical studies (19). Intermolecular disulfide cross-linking close to the $\mathrm{C}$-terminal heparin-binding domain is the oligomerization force of $\mathrm{Vn}$. This study showed that pHBD mediated the association of the rhHAPO dimer into a tetramer. We proposed a potential model to account for the oligomerization of rhHAPO (Fig. 4). The subunits of rhHAPO were assembled post-translationally into a dimer by interactions between SMB domains, and this interaction caused a conformational change of pHBD which mediated the association of the rhHAPO dimer into a tetramer.

Taken together, these observations demonstrate that rhHAPO is a stable $129-\mathrm{kDa}$ noncovalent homological oligomer. Initially self-associated rhHAPO dimers are formed by interactions between SMB domains, whereas the formation of a tetramer is a secondary event mediated by pHBD sequences. Tetrameric rhHAPO is more potent in promoting the adhension of HESS-5 cells compared with dimeric rhHAPO. Dimeric rhHAPO does not bind heparin, while tetrameric rhHAPO has a high affinity for heparin although there are no clear conformational changes.

\section{Acknowledgements}

This study was supported by the National Natural Science Foundation of Zhejiang, no. LQ12H16001 and Zhejiang Provincial Program for the Cultivation of High-level Innovative Health talents.

\section{References}

1. Liu YJ, Lu SH, Xu B, Yang RC, Ren Q, Liu B, Li B, Lu M, Yan FY, Han ZB and Han ZC: Hemangiopoietin, a novel human growth factor for the primitive cells of both hematopoietic and endothelial cell lineages. Blood 103: 4449-4456, 2004.

2. Flannery CR, Hughes CE, Schumacher BL, Tudor D, Aydelotte MB, Kuettner KE and Caterson B: Articular cartilage superficial zone protein (SZP) is homologous to megakaryocyte stimulating factor precursor and is a multifunctional proteoglycan with potential growth-promoting, cytoprotective, and lubricating properties in cartilage metabolism. Biochem Biophys Res Commun 254: 535-541, 1999.

3. Ikegawa S, Sano M, Koshizuka Y and Nakamura Y: Isolation, characterization and mapping of the mouse and human PRG4 (proteoglycan 4) genes. Cytogenet Cell Genet 90: 291-297, 2000
4. Jay GD, Tantravahi U, Britt DE, Barrach HJ and Cha CJ: Homology of lubricin and superficial zone protein (SZP): products of megakaryocyte stimulating factor (MSF) gene expression by human synovial fibroblasts and articular chondrocytes localized to chromosome 1q25. J Orthop Res 19: 677-687, 2001.

5. Rees SG, Davies JR, Tudor D, Flannery CR, Hughes CE, Dent CM and Caterson B: Immunolocalisation and expression of proteoglycan 4 (cartilage superficial zone proteoglycan) in tendon. Matrix Biol 21: 593-602, 2002.

6. Panagopoulos I, Mertens F, Isaksson M and Mandahl N: Expression of DOL54 is not restricted to myxoid liposarcomas with the FUS-DDIT3 chimera but is found in various sarcomas. Oncol Rep 12: 107-110, 2004.

7. Zhan M and Han ZC: Hemangiopoietin inhibits apoptosis of MO7e leukemia cells through phosphatidylinositol 3-kinase-AKT pathway. Biochem Biophys Res Commun 317: 198-204, 2004

8. Xu ZS, Liu YJ, Lv LL, Han ZB, He R, Lu SH, Wang T, Xu B Chen ZZ and Han ZC: Bone marrow stromal cells transduced with human hemangiopoietin gene support hematopoiesis in vitro. Haematologica 90: 157-165, 2005.

9. Guo NH, Krutzsch HC, Nègre E, Zabrenetzky VS and Roberts DD: Heparin-binding peptides from the type I repeats of thrombospondin. Structural requirements for heparin binding and promotion of melanoma cell adhesion and chemotaxis. J Biol Chem 267: 19349-19355, 1992.

10. Shimakura Y, Kawada H, Ando K, Sato T, Nakamura Y, Tsuji T, Kato S and Hotta T: Murine stromal cell line HESS-5 maintains reconstituting ability of ex vivo-generated hematopoietic stem cells from human bone marrow and cytokine-mobilized peripheral blood. Stem Cells 18: 183-189, 2000.

11. Völker W, Hess S, Vischer P and Preissner KT: Binding and processing of multimeric vitronectin by vascular endothelial cells. J Histochem Cytochem 41: 1823-1832, 1993.

12. Seiffert D: The glycosaminoglycan binding site governs ligand binding to the somatomedin B domain of vitronectin. J Biol Chem 272: 9971-9978, 1997.

13. Deng G, Curriden SA, Hu G, Czekay RP and Loskutoff DJ: Plasminogen activator inhibitor-1 regulates cell adhesion by binding to the somatomedin B domain of vitronectin. J Cell Physiol 189: 23-33, 2001.

14. Zanetti A, Conforti G, Hess S, Martìn-Padura I, Ghibaudi E, Preissner KT and Dejana E: Clustering of vitronectin and RGD peptides on microspheres leads to engagement of integrins on the luminal aspect of endothelial cell membrane. Blood 84: 1116-11123, 1994.

15. Burke C, Mayo KH, Skubitz AP and Furcht LT: 1H NMR and CD secondary structure analysis of cell adhesion promoting peptide F-9 from laminin. J Biol Chem 266: 19407-19412, 1991.

16. Bittorf SV, Williams EC and Mosher DF: Alteration of vitronectin. Characterization of changes induced by treatment with urea. J Biol Chem 268: 24838-24846, 1993.

17. Zhuang P, Chen AI and Peterson CB: Native and multimeric vitronectin exhibit similar affinity for heparin. Differences in heparin binding properties induced upon denaturation are due to self-association into a multivalent form. J Biol Chem 272: 6858-6867, 1997.

18. Preissner KT and Jenne D: Structure of vitronectin and its biological role in haemostasis. Thromb Haemost 66: 123-132, 1991.

19. Zhuang P, Blackburn MN and Peterson CB: Characterization of the denaturation and renaturation of human plasma vitronectin. I. Biophysical characterization of protein unfolding and multimerization. J Biol Chem 271: 14323-14332, 1996.

20. Guex N and Peitsch MC: SWISS-MODEL and the Swiss-Pdb Viewer: an environment for comparative protein modeling. Electrophoresis 18: 2714-2723, 1997.

21. Horn NA, Hurst GB, Mayasundari A, Whittemore NA, Serpersu $\mathrm{H}$ and Peterson CB: Assignment of the four disulfides in the N-terminal somatomedin B domain of native vitronectin isolated from human plasma. J Biol Chem 279: 35867-35878, 2004.

22. Kamikubo Y, Okumura Y and Loskutoff DJ: Identification of the disulfide bonds in the recombinant somatomedin B domain of human vitronectin. J Biol Chem 277: 27109-27119, 2002.

23. Kamikubo Y, De Guzman R, Kroon G, Curriden S, Neels JG, Churchill MJ, Dawson P, Ołdziej S, Jagielska A, Scheraga HA, Loskutoff DJ and Dyson HJ: Disulfide bonding arrangements in active forms of the somatomedin B domain of human vitronectin. Biochemistry 43: 6519-6534, 2004.

24. Gijsbers R, Ceulemans H and Bollen M: Functional characterization of the non-catalytic ectodomains of the nucleotide pyrophosphatase/phosphodiesterase NPP1. Biochem J 371: 321-330, 2003 . 